\title{
Avaliação de projetos pedagógicos: estudo nos cursos de Bacharelado
}

\author{
Interdisciplinar em Saúde
}

\section{Evaluation of pedagogical projects: a study concerning the Bachelor Interdisciplinary Courses of Health Sciences}

\author{
Regina Bittencourt*,**, Maria Alves** \\ *Universidade do Minho, ${ }^{* *}$ Universidade Federal do Recôncavo da Bahia
}

\begin{abstract}
Resumo
Trata-se de um estudo de caso, com abordagem quantiqualitativa. Os dados foram recolhidos através da análise documental dos Projetos Pedagógicos dos Cursos (PPCs) dos Bacharelados Interdisciplinares em Saúde (BIS) da da Universidade Federal do Recôncavo da Bahia (UFRB), dos documentos normativos para o desenvolvimento de competências e de inquéritos por entrevistas e questionários. Os dados foram tratados com recurso à análise de conteúdo e à estatística descritiva. Os resultados da investigação sugerem que os PPCs dos cursos apresentam propostas curriculares integradas, com enfoque na interdisciplinaridade, atividades e avaliação formativa; os docentes responsáveis pela reformulação e desenvolvimento do currículo não consideram o perfil do estudante; enfatiza-se a oralidade em detrimento da escrita académica, nas práticas pedagógicas
\end{abstract}

Palavras chave: Avaliação, Currículo, Projeto Pedagógico Interdisciplinar, Competência Comunicativa

\begin{abstract}
It's a case study, using a quantitative-qualitative approach. Data were collected from the Pedagogical Projects of the Courses (PPCs), the normative documents concerning the development of competence, interviews and questionnaires. Data were analyzed using content analysis and descriptive statistics for closed questions. The main results suggest the PPCs propose integrated activities, focusing on interdisciplinary, as well as strategies of formative assessment, that favor the development of communicative competence; teachers responsible for reformulation and curriculum development do not consider the profile of the student; pedagogical practices emphasize orality, to the detriment of academic writing.

Keywords: Evaluation, curriculum, Pedagogical Projects, Interdisciplinary, Communicative Competence
\end{abstract}

\section{Introdução}

Esta investigação surge da constatação, a partir de resultados de avaliações externas ( entre 2007 e 2014) tais como, o Programme for International Student Assessment (PISA), o Exame Nacional do Ensino Médio (ENEM) e o Exame Nacional de Desempenho dos Estudantes (ENADE), que os estudantes oriundos do ensino médio nacional, em particular, da região Nordeste, potenciais ingressantes no ensino superior, ingressantes da UFRB e seus egressos têm apresentado debilidades em competências comunicativas, em níveis que não condizem com o que está proposto nos documentos normativos nacionais que orientam o desenvolvimento destas competências. Nesta contextualização, no bojo das reformas no ensino superior no Brasil, no final da década de 1990, os Bacharelados Interdisciplinares (BI) surgem como uma proposta curricular inovadora, integrada, com foco na formação geral, planificada com propostas pedagógicas interdisciplinares que propiciam aos estudantes experiências, e contribuem para o desenvolvimento de competências gerais e transversais, a fim de superar os principais desafios da formação de pessoal de nível superior.

Além disso, apesar de analisarmos uma Instituição Federal de Ensino Superior (IFES) e sabermos que os seus ingressantes podem ser oriundos de qualquer parte do país, os dados da Pró-Reitoria de Graduação da UFRB $^{1}$ revelam que a maior parte dos seus estudantes (92\%) é do próprio estado da Bahia, o maior estado da região Nordeste.

Se se consideram os dados de desempenho nas habilidades de leitura e escrita em língua materna dos ingressantes, então é necessário que se analisem os dados dos concluintes (egressos), uma vez que se objetiva identificar e avaliar estratégias pedagógicas nos Projetos Pedagógicos dos Cursos do BIS que se proponham desenvolver a competência comunicativa, formando cidadãos críticos e reflexivos, que contribuam para a sua formação académica e, posteriormente, para o exercício profissional. Para tanto, tomar-se-ão os dados do ENADE (Exame Nacional de Desempenho de Estudantes), uma vez que tem por objetivo aferir o desempenho dos estudantes em relação aos conteúdos programáticos previstos nas diretrizes curriculares dos respectivos cursos de graduação, bem como, as competências para compreender temas exteriores ao âmbito específico da sua profissão.

1 Dados da Pró-reitoria de graduação da UFRB, e de Santos (2013). 
Além disso, em 2012, a UFRB fez um levantamento das notas de Formação Geral da prova do ENADE de todos os cursos e concluiu que a instituição estava a contribuir muito pouco para a formação geral dos estudantes e, em alguns cursos, a contribuição era praticamente nula, sendo este um dos motivos da reformulação curricular nos cursos do BIS, Enfermagem, Nutrição e Psicologia, que ocorreu em 2014, a qual ocasionou a formação em ciclos, tornando os cursos lineares em segundo ciclo do BIS.

Esta realidade motivou a presente pesquisa a analisar, inicialmente, com recurso a documentos supranacionais, nacionais e institucionais o enfoque dado pelas políticas curriculares ao desenvolvimento da competência de comunicação dos estudantes, para os projetos pedagógicos dos cursos de graduação (PPCs), e avaliar o modo como essa competência se apresenta nos PPCs dos cursos do Bacharelado Interdisciplinar em Saúde, da UFRB.

O caso em estudo é o da avaliação dos Projetos Pedagógicos dos cursos do Bacharelado Interdisciplinar em Saúde (BIS) da UFRB, a saber: além do próprio BIS, os cursos de Enfermagem, Nutrição e Psicologia, antes e após a reformulação curricular pela qual passaram em 2014.

\section{Objetivos}

A partir dessa análise e avaliação, buscou-se, a partir de inquéritos com docentes e discentes, constatar como se desenvolve e avalia essa competência ao longo do curso, e, em seguida, triangular os dados obtidos a partir dessas análises e recolha.

Neste enquadramento, formulou-se a problemática: poderá um processo de desenvolvimento curricular integrado, sustentado em trabalhos interdisciplinares que incluam uma forte componente de avaliação processual com função reguladora e metacognitiva, contemplar processos e práticas sustentadas de desenvolvimento de competência comunicativa? Essa questão arrastou questões subsidiárias, tais como: Os Projetos Pedagógicos dos cursos (PPCs) do Bacharelado Interdisciplinar em Saúde (BIS) têm propostas de desenvolvimento de competência comunicativa coerentes com as concepções de competência comunicativa dos exames que lhe servem como instrumentos de avaliação, bem como com as propostas preconizadas pelos documentos normativos nacionais e institucionais? Como se desenvolve e avalia essa competência ao longo do processo de desenvolvimento curricular? Por que está sendo desenvolvida, ou seja, quais referenciais norteadores: perfil do ingressante, perfil do egresso, ou apenas seguir as orientações dos documentos normativos? Qual o enfoque dado ao desenvolvimento da competência comunicativa antes e após a reformulação curricular?

A fim de responder a essas questões, os seguintes objetivos foram traçados: a) analisar as concepções do MEC (ENEM, ENADE) e PISA sobre competência comunicativa, e propostas dos demais documentos institucionais dos cursos (BIS, Enfermagem, Nutrição e
Psicologia) para o desenvolvimento de competência comunicativa; b) avaliar a importância atribuída pelos docentes, coordenadores dos cursos e membros dos Núcleos Docentes Estruturantes (NDE) quanto ao domínio da competência comunicativa pelos discentes, bem como estratégias de desenvolvimento e avaliação dessa competência, nos PPCs; c) avaliar a percepção dos estudantes sobre o desenvolvimento da sua competência comunicativa após ingressar no curso.

\section{Método}

Dados os objetivos da pesquisa, tratou-se de um estudo de caso e, portanto, optou-se por uma abordagem metodológica quanti-qualitativa, combinando técnicas e metodologias diferentes, ou seja, buscando um modo integrado de pesquisa, reconhecendo, contudo, a predominância da abordagem qualitativa, e análise documental e de conteúdo (entrevistas e questionários) como técnicas de recolha de dados. Ou seja, estudo basicamente qualitativo, de natureza descritiva e interpretativa, a fim de retratar um aspecto da realidade de uma organização.

Recorreu-se à análise documental dos PPCs do BIS, bem como aos documentos normativos para o desenvolvimento de competência, tendo sido aplicados inquéritos por entrevistas e questionários a uma amostra de 6 docentes e inquéritos por questionário a 73 estudantes. Os dados foram tratados com recurso à estatística descritiva para as questões fechadas e à análise de conteúdo para as entrevistas e questões abertas do questionário.

\section{Participantes}

Tendo em vista um dos objetivos desta pesquisa que é: avaliar a importância atribuída pelos docentes, coordenadores dos cursos e membros dos Núcleos Docentes Estruturantes (NDE) quanto ao domínio das competências de comunicação pelos estudantes dos cursos, bem como, avaliar a percepção dos estudantes sobre o desenvolvimento de sua competência comunicativa antes e após ingressar no curso, então a população a ser pesquisada foi constituída por docentes e discentes, atores diretamente envolvidos no processo de ensino-aprendizagem-desenvolvimento de tais competências.

A população-alvo é composta por docentes dos Bacharelados Interdisciplinares e dos cursos do segundo ciclo (Nutrição, Psicologia e Enfermagem). Já a população acessível será composta por Docentes dos Núcleos Docentes Estruturantes (NDE) ${ }^{2}$; Coordenadores de Curso; Coordenadores de Áreas de conhecimento; e docentes dos cursos, além dos discentes.

Os docentes que não participaram do desenvolvimento dos PPCs e não são membros do NDE ficaram no grupo denominado Formadores, enquanto que os docentes que atuam como coordenadores são membros do NDE, ou participaram do desenvolvimento dos PPCs, ficaram no grupo Avaliadores.

Desta forma, a amostra de docentes avaliadores acabou ficando composta por 4 docentes, todos do gênero 
feminino e apenas uma não ensinou no BIS, todas eram ou haviam sido membros do NDE e coordenadoras. Além disso, considerou-se o tempo de ensino, que ficou em torno de 10 anos, ensino na UFRB (média de 6 anos) e a idade (entre 39 e 47 anos)

A amostra de discentes foi composta por 73 , sendo que o total de estudantes inquiridos por curso ficou assim distribuído: BIS, 27; Enfermagem, 15; Psicologia, 17; Nutrição, 14. No geral, são maioritariamente do sexo feminino $(78,1 \%)$, jovens entre 21 e 24 anos $(41,1 \%)$, sendo que os estudantes mais jovens se encontram no curso do primeiro ciclo (BIS) e ingressaram pelo Sistema de Seleção Unificado (SiSU), a partir da prova do ENEM.

\section{Instrumentos}

A recolha de dados desta pesquisa recorreu aos seguintes instrumentos: a) entrevistas abertas, subjetivas; b) questionários; c) documentos (DCNs e PPCs); d) observação participante.

A entrevista e o questionário perseguem os seguintes objetivos desta pesquisa: avaliar a importância atribuída pelos docentes, coordenadores dos cursos e membros dos Núcleos Docentes Estruturantes quanto ao domínio da competência comunicativa pelos discentes, bem como estratégias de desenvolvimento e avaliação dessa competência, nos cursos em estudo; avaliar a percepção dos discentes sobre o desenvolvimento de sua competência comunicativa após ingressar no curso.

\section{Procedimento}

A abordagem quantitativa foi aplicada para as questões objetivas do questionário. As questões quantitativas analisadas referem-se à frequência com que as atividades e instrumentos de avaliação estão voltados para o desenvolvimento da competência comunicativa, o que foi analisado com base nos questionários aplicados aos discentes.

De um total de 30 docentes contatados, apenas 05 agendaram a entrevista. Sendo assim, a estratégia adotada foi encontrá-los diretamente no Centro de Ensino no período de aulas para fazer a entrevista, e fazer o convite pessoalmente para aqueles que iriam responder ao questionário.

Apesar de o questionário apresentar a vantagem em relação à entrevista de não requerer maior disponibilidade de tempo e não causar inibição, devido ao formalismo da situação, apenas 2 docentes se dispuseram a responder no mesmo dia da entrega do questionário. Os demais, que ficaram de devolver o questionário, assim não procederam, mesmo sendo dado um tempo de quase um mês para retorno. Quanto a essa baixa taxa de respostas, considera-se que o trabalho docente se caracteriza por excesso de atividades, além do ensino, tais como pesquisa, extensão e produtividade académica.

O questionário foi dividido por blocos com os seguintes temas: Competências; Competência comunicativa; Avaliação, e Desenvolvimento curricular/currículo integrado. O objetivo foi entrevistar os docentes que participaram e vivenciaram direta e ativamente da criação, implantação, desenvolvimento e avaliação dos cursos e currículos. Aos docentes avaliadores foi aplicado o inquérito por entrevista cujo objetivo principal era avaliar a importância atribuída pelos docentes, coordenadores dos cursos e membros dos NDE quanto ao domínio da competência comunicativa pelos discentes, bem como estratégias de desenvolvimento e avaliação dessa competência, nos cursos em estudo.

Nesta pesquisa utilizamos, como técnicas de análise de dados, a análise de conteúdo e a estatística descritiva. A análise de conteúdo foi utilizada para tratamento das entrevistas, para questões abertas, subjetivas, dos questionários, para a observação participante e análise dos documentos. Já o procedimento para análise dos dados recolhidos através das questões fechadas/objetivas do questionário discente, recorreu-se ao Statistical Package for the Social Sciences - SPSS (versão 22 para Windows).

Após a leitura das questões abertas/subjetivas dos questionários e das entrevistas, foi feita a interpretação do conteúdo, através de inferência. Assim, a análise do conteúdo baseada na inferência, mediou a descrição e a interpretação, a fim de se chegar a uma leitura consistente e representativa do real. Desta forma, a análise de conteúdo baseou-se em operações de desmembramento do texto em categorias, quantificação de dados e inferência para a interpretação, o que permitiu a descrição objetiva, sistemática e quantitativa do conteúdo analisado.

A análise de documentos incluiu todos os documentos oficiais, legislação, documentos institucionais. A análise documental teve como fito complementar informações obtidas pela entrevista e inquérito por questionário, o que favoreceu à minimização do excesso de subjetividade, a fiabilidade e triangulação dos dados, além de que algumas informações só poderia ser adquiridas através dessas fontes e por essa análise, que pode resultar de uma análise parcelar de informações

\section{Apresentação e discussão dos resultados}

Os resultados da investigação sugerem que os PPCs dos cursos apresentam-se integradores, com enfoque na interdisciplinaridade, apresentando uma ampliação em atividades e avaliações formativas que favorecem o desenvolvimento da competência comunicativa; os docentes responsáveis pela reformulação e desenvolvimento curricular não consideram o perfil do ingressante, o que dificulta a implementação de propostas que favoreçam a literacia académica dos discentes, posto que se verificou uma ênfase na oralidade em detrimento da escrita académica, nas práticas pedagógicas.

Outros resultados importantes são as notas e médias dos ingressantes do Centro de Ciências da Saúde da UFRB, de 2010 a 2014, no ENEM, para as provas de Linguagens e Redação. Para a prova de Linguagens, nota-se que, de um modo geral, a média dos ingressantes do CCS sempre esteve acima da média nacional, e, assim como esta, também apresentou, ao longo dos anos, uma flutuação nas médias com tendência a diminuição. Isso revela que, ao longo dos anos, os ingressantes apresentaram maiores debilidades em linguagens do que 
nos anos anteriores e a instituição precisava estar atenta a essas necessidades, reorganizando seus currículos.

Já os ingressantes dos cursos de Enfermagem, Nutrição e Psicologia apresentaram leve e constante queda nas notas de Redação ao longo dos anos, indicando estudantes com níveis de competência comunicativa cada vez menores, o que requeriria mais atenção da IFES, no tocante ao desenvolvimento dessa competência ao longo do curso.

Em suma: ao longo dos anos, as médias, em relação à competência comunicativa em língua portuguesa, parecem revelar que os ingressantes têm apresentado cada vez menor domínio da norma culta da Língua Portuguesa; dificuldades incompatíveis com as competências da Matriz de Referência para a prova de Redação do ENEM, que prevê as habilidades e competências para organizar, relacionar, interpretar dados e informações; construir argumentação consistente, elaborar críticas, confrontar opiniões e pontos de vista em elaborar propostas, dentre outras. Em relação à matriz de referência para a prova discursiva (Redação), as debilidades podem estar associadas à dificuldade em elaborar texto de tipologia dissertativoargumentativa, em elaborar uma proposta de intervenção social.

De um modo geral, as notas dos egressos (ENADE) e a percepção dos estudantes sobre o curso revelam que houve pouca contribuição para a formação geral e para o desenvolvimento em competência comunicativa dos estudantes desses cursos até 2013. Ou seja, além dos dados do PISA e do ENEM (ingressantes na UFRB), que revelam debilidades em competências de comunicação de estudantes egressos do ensino médio, debilidades em competência comunicativa também podem ser inferidas para estudantes egressos dos cursos de Enfermagem, Nutrição e Psicologia (entre os anos de 2010 e 2013), através das notas do ENADE, em Formação Geral, prova com questões de natureza transdisciplinar que avalia fortemente habilidades de leitura, interpretação e interpretação de textos; argumentação e elaboração de sínteses, em suma, competência comunicativa.

Já os PPCs revelam que há, no primeiro ciclo (BIS), componentes que favorecem ao desenvolvimento dessa competência, além dos componentes relacionados ao TCC e ao Estágio, o que amplia a gama de oportunidades de desenvolvimento da competência comunicativa dos estudantes. A arquitetura curricular proposta na UFRB é uma estrutura modular, interdisciplinar, flexível e progressiva, com garantia de mobilidade intra e interinstitucional. $O$ primeiro ciclo também se caracteriza por ser um período de formação propedêutica, período de formação geral, com espaço para a formação cultural humanística, com um módulo voltado ao desenvolvimento da linguagem.

A estrutura curricular do BIS contempla um eixo integrador comum formado pelos módulos- Processos de Apropriação da Realidade -PAR. O PAR é articulado em torno de problemas, questões ou temas socialmente relevantes para os estudantes, e funcionam como núcleos ou eixos integradores em tomo dos quais se articula e sequencializa o processo curricular. Estruturado curricularmente de forma integrada, com articulação vertical (continuidade curricular) e horizontal (interdisciplinaridade e transversalidade) dos diferentes conhecimentos e capacidades a desenvolver nos processos de ensino-aprendizagem, mostra "uma sequência progressiva e interligada entre as diferentes unidades, numa perspectiva globalizadora e integradora do saber e da experiência", conforme Alonso (2004). Isto é, são módulos eminentemente práticos que envolvem ensino, pesquisa e extensão, promovendo a integralização dessas atividades no currículo. Além disso, os trabalhos produzidos nos módulos PAR são socializados no final de cada semestre letivo, em um evento académico denominado Seminário Integrativo do BIS. O evento tem por objetivo divulgar os trabalhos interdisciplinares desenvolvidos pelos estudantes e que favoreçam o desenvolvimento da competência comunicativa nas modalidades oral e escrita da língua. $\mathrm{O}$ que se observou quanto ao eixo integrador (módulos do PAR) é que os docentes devem trabalhar numa pedagogia da integração e numa abordagem por competências, pois, esse eixo:

- estimula o desenvolvimento das competências nos estudantes, ao mobilizar os seus recursos em situações complexas;

- apresenta aprendizagens significativas;

- envolve os estudantes em atividades de pesquisa, em projetos de conhecimento; e

- estimula os estudantes a enfrentar e analisar, em conjunto, situações complexas, práticas e problemas profissionais.

Fica claro, a partir desse componente, que o objetivo do currículo integrado é o desenvolvimento de competências, pois nele há, também, a resolução de problemas inerentes à comunidade em que está inserida a UFRB. Também busca dar significado às demais disciplinas, posto que se mobilizam de forma integrada vários recursos para "encarar diferentes situações significativas". Além disso, nesses módulos pretende-se articular as atividades de pesquisa e extensão com o desenvolvimento da linguagem, bem como, "o uso da norma culta como instrumento de comunicação oral e escrita".

O Portefólio Reflexivo Integrador (PRI), construído processualmente, tem como objetivo demonstrar as competências adquiridas e desenvolver o pensamento crítico-reflexivo, além disso, consiste em uma produção de caráter obrigatório, e deve ser apresentado no final do primeiro ciclo. Uma dessas competências é a comunicativa, uma vez que se trata de um documento que deve ser redigido na norma culta da língua, em linguagem académica e apresentado oralmente para uma banca.

Além desse instrumento, outros e atividades avaliativas estão previstas, como a Avaliação Integrativa, um instrumento individual, aplicado em todos os semestres, que visa integrar os conteúdos, tendo os estudantes que construir um texto dissertativo que apresente uma análise integrada de uma situação-problema, articulando-a aos conhecimentos construídos nos módulos. Essa é mais uma atividade em que o desenvolvimento da competência comunicativa é favorecido, em particular na modalidade escrita, em uma tipologia (dissertativa) que 
favorece o pensamento crítico-reflexivo e a argumentação.

Nota-se, pois, que a avaliação tende a ser formativa, e reguladora, que permite o ajuste de métodos e a alteração de ritmos (Alves \& Machado, 2008). A avaliação formativa "deve ser parte integrante do processo de ensino e de aprendizagem" (Alves, 2004, p.36), como reguladora destes processos, atuando para a melhoria do ensino e da aprendizagem permeia todo no processo ensino-aprendizagem.

Inicialmente é preciso estar atento ao facto de que os inquéritos (entrevistas e questionários) não dizem o que realmente acontece, mas o que as pessoas dizem que acontece, sendo, por isso, as suas percepções a respeito dos factos.

A partir das entrevistas e dos questionários com docentes e discentes, pode depreender-se que a dificuldade com a comunicação oral tem sido identificada e bem trabalhada pelos docentes, que incentivam apresentações orais (individuais e em grupos), debates sobre temas e textos, o que requer dos estudantes leituras, elaboração de sínteses e fichamentos, havendo, no entanto, pouca ênfase na elaboração de textos que desenvolvam a capacidade crítica, a argumentação, mais voltados para a linguagem académica, tais como, artigos, resenhas e ensaios, tornando-os outsiders (Gee, 2000) da literacia académica.

Essas debilidades ficaram evidentes tanto nos questionários dos estudantes, quanto nos dados do ENEM e ENADE os quais revelam que as debilidades gerais em competência comunicativa dos potenciais ingressantes, graduandos e egressos dos cursos do BIS são as de construir argumentação consistente, elaborar críticas, confrontar opiniões e pontos de vista em elaborar propostas, sendo essas as maiores dificuldades elencadas pelos discentes que, dentro da perspectiva da literacia académica, estão relacionadas com a elaboração de textos de tipologia dissertativo-argumentativa.

Assim, a competência comunicativa apresentou propostas de desenvolvimento, não somente a partir de componentes, mas também através de módulos e atividades interdisciplinares, ao longo de todo o curso, e em componentes voltados especificamente para a linguagem, como na componente Oficina de leitura e produção de textos académicos, e em atividades pedagógicas e avaliações, tais como, o módulo PAR, seminários integrativos e o Portefólio Reflexivo Integrador (PRI).

Além dessas componentes inerentes ao desenvolvimento da competência comunicativa, percebese que atividades como o PRI, a Avaliação Integrativa e a participação nos Seminários Integrados, cujos produtos são a produção de portefólios, textos dissertativos e apresentação oral de trabalhos académicos, favorecem o desenvolvimento da competência comunicativa enquanto competência transversal.

Por fim, quanto à questão maior, verificou-se inicialmente que há um processo de desenvolvimento curricular integrado (módulos e eixos), sustentado em trabalhos interdisciplinares (portefólio integrativo, portefólio reflexivo integrador individual, seminário integrativo e avaliação integrativa), que incluem uma forte componente de avaliação processual com função reguladora, como, por exemplo, o portefólio, que podem contemplar processos e práticas de desenvolvimento de competência comunicativa.

\section{Conclusões}

Constata-se, pois, que os PPCs dos cursos do BIS, são "terrenos" propícios ao desenvolvimento da competência comunicativa, através de práticas avaliativas formativas e formadoras, centradas em temas integradores e trabalhos transdisciplinares, isto é, que podem contemplar práticas de desenvolvimento da competência comunicativa, no entanto, estão a ser utilizados aquém das suas potencialidades. Às atividades, avaliações e módulos já existentes, como o PAR, à formação integrada à realidade social, juntam-se o evento académico denominado Seminário Integrativo, que favorece o desenvolvimento da oralidade e da escrita, pois além das apresentações dos seminários, tem como um dos produtos avaliativos o Portefólio Reflexivo Integrador (PRI), construído processualmente e redigido na norma culta da língua, e em linguagem académica; bem como a Avaliação Integrativa, um instrumento individual, aplicado em todos os semestres, que visa integrar os conteúdos, tendo os estudantes que construir um texto dissertativo.

De acordo com as entrevistas, o perfil do ingressante (a partir de resultados do ENEM) quando é considerado, é pouco ou quase nada explorado para orientar as reformulações e desenvolvimento curricular, o que não deveria ser, pois, segundo Luckesi (1999, p.9) sobre o ato de avaliar: "não é possível uma decisão sem um diagnóstico" e para Roldão (2008, pp.77-78) a primeira fase do desenvolvimento curricular é a fase da sua concepção, para a qual deve haver uma análise da situação, que inclui "ter em conta a realidade dos alunos".

Segundo os docentes, desenvolvem-se práticas que favorecem o trabalho com a competência comunicativa, em especial, a oralidade e a adequação do vocabulário à linguagem académica.

A leitura é pré-requisito para o trabalho da oralidade, muito avaliada pelos docentes.

Nos cursos do segundo ciclo, de acordo com o que se verificou nos PPCs, as atividades integradas e interdisciplinares são mais escassas e a competência comunicativa parece ser mais desenvolvida nos seminários e debates, quando da produção de textos técnicos, tais como, práticas de laboratório, elaboração de projetos, relatórios.

Quanto à escrita, conforme entrevista e questionários dos estudantes, apesar de muito solicitada para a atividade do portefólio, que também favorece e estimula a criticidade e o pensamento reflexivo do estudante ao tomar decisões e resolver problemas reais, este parece ser um dos raros momentos em que se trabalha a escrita que favorece a capacidade de elaborar críticas, conforme se verificou nas percepções dos estudantes.

Isto é, há pouca variedade de trabalhos com géneros académicos que favoreçam a argumentação, a linguagem eminentemente académica e a criticidade. Isso dificulta a 
apropriação de práticas discursivas escritas, da esfera académica, a literacia académica tem de ser vista como um vasto repertório de práticas especializadas e convencionadas que os estudantes têm de desenvolver como condição para a sua afiliação académica e para se assumirem como produtores de conhecimentos científicos e profissionais.

De facto, a competência comunicativa, em especial, no primeiro ciclo, eminentemente interdisciplinar, é desenvolvida em práticas avaliativas centradas numa atividade ou num tema integrador, de forma processual, que favorecem a maior participação dos estudantes (avaliação formativa), com instrumentos de avaliação tais como portefólios, apresentações orais e textos dissertativos e técnicos.

No entanto, verificou-se que há uma ênfase na oralidade, em detrimento da escrita académica. No geral, na percepção dos estudantes sobre o desenvolvimento de sua competência comunicativa é razoável, visto que algumas de suas dificuldades têm sido sanadas através de atividades adequadas, no entanto, outras mais complexa,s ainda não foram trabalhadas pelos docentes, cujas práticas e metodologias não são direcionadas ao atendimento dessas dificuldades.

\section{Agradecimentos}

Este trabalho foi financiado por Fundos Nacionais através da FCT (Fundação para a Ciência e a Tecnologia) e cofinanciado pelo Fundo Europeu de Desenvolvimento Regional (FEDER) através do COMPETE 2020 Programa Operacional Competitividade e Internacionalização (POCI) no âmbito do CIEC (Centro de Investigação em Estudos da Criança da Universidade do Minho) com a referência POCI-01-0145-FEDER007562.

\section{Referências}

Alves, M.P. (2004) Currículo e Avaliação: Uma perspectiva integrada. Porto: Porto Editora

Alves, M.P. \& Machado, E.A. (2008). Avaliação com sentidos: Contributos e Questionamentos. Santo Tirso: De Facto Editores.

Gee, J. P. (2000). The new literacy studies: From" socially situated" to the work of the social. In Barton, M. Hamilton \& R. Ivanic ( Eds.) Situated literacies: Reading and writing in context (pp.180-196). New York: Routledge. Disponível em: http://jamespaulgee.com/geeimg/pdfs/The $\% 20$ New\% 20Literacy $\% 20$ Studies $\% 20$ and $\% 20$ the $\% 20$ Social $\% 20$ Turn.pdf, Acedido em 28 de novembro 2016

Luckesi,C. C. (1999). Avaliação da aprendizagem escolar. 9. ed. São Paulo: Cortez.

Roldão, M. C. (2008). Gestão do Currículo e Avaliação de Competências - As questões dos professores. Lisboa: Editorial Presença. 